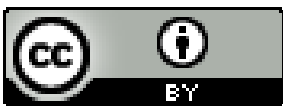

\title{
SOCIOLOGIA AFRICANA: DO GENITIVO DO OBJECTO AO GENITIVO DO SUJEITO
}

\author{
Sebastião Merlen ${ }^{1}$ \\ Universidade Agostinho Neto, Faculdade de Ciências Sociais, Departamento de \\ Sociologia, Luanda, Angola
}

Resumo: O presente texto, com base numa discussão bibliográfica e com recurso ao critério histórico, propõe uma reflexão sobre a sociologia africana, tendo em atenção o processo de formação, desenvolvimento, profissionalização e afirmação desta ciência social em África. Destaca três perspectivas para o estudo e ensino da sociologia africana e enfatiza o papel da prática de uma sociologia africana por parte dos sociólogos africanos, bem como dos profissionais envolvidos no processo de ensino $\mathrm{e}$ aprendizagem da sociologia em África, para mitigar os efeitos da dependência académica e para resistir ao eurocentrismo e ao imperialismo académico da actual geopolítica da produção do conhecimento.

Palavras-Chave: África; Dependência académica; Geopolítica do conhecimento; Imperialismo académico; Sociologia Africana.

\section{AFRICAN SOCIOLOGY: FROM OBJECTIVE GENITIVE TO SUBJECTIVE GENITIVE}

\begin{abstract}
Based on a bibliographical discussion and using historical criteria, this text proposes a reflection on African sociology, taking into account the process of formation, development, professionalization and affirmation of this social science in Africa. The text highlights three perspectives for the study and teaching of African sociology and emphasizes the role of the practice of African sociology by African sociologists, as well as by professionals involved in the process of teaching and learning sociology in Africa, as a way to reduce the effects of academic dependence and to resist the Eurocentrism and academic imperialism of the current geopolitics of knowledge production.
\end{abstract}

Keywords: Academic dependency; Academic imperialism; Africa; African Sociology; Geopolitics of knowledge.

\footnotetext{
${ }^{1}$ Assistente na Faculdade de Ciências Sociais da Universidade Agostinho (FCS-UAN). Mestrando em Sociologia pela Faculdade de Ciências Sociais da Universidade Agostinho (FCS-UAN); licenciado em Ciências da Educação (opção: Ensino da Sociologia) pelo Instituto Superior de Ciências da Educação (ISCED) de Luanda. Realiza actividades de ensino e pesquisa voltadas para a história da sociologia, pensamento sociológico angolano, pensamento pós-colonial, sociologia africana e teorias sociológicas. E-mail: sebastiao.merlen@ yahoo.com ; ORCID: https://orcid.org/0000-0002-9927-2430
} 


\section{Otyronom SOCIOLOGÍA AFRICANA: DEL GENITIVO DEL OBJETO AL GENITIVO DEL SUJETO}

Resumen: Este texto, basado en una discusión bibliográfica y utilizando criterios históricos, propone una reflexión sobre la sociología africana, teniendo en cuenta el proceso de formación, desarrollo, profesionalización y afirmación de esta ciencia social en África. Destaca tres perspectivas para el estudio y la enseñanza de la sociología africana y enfatiza el papel de la sociología africana en la práctica de los sociólogos africanos, así como de los profesionales involucrados en el proceso de enseñanza y aprendizaje de la sociología en África, para mitigar los efectos de la dependencia académica. y resistir el eurocentrismo y el imperialismo académico de la actual geopolítica de producción de conocimiento.

Palabras-clave: África; Dependencia académica; Geopolítica del conocimiento; Imperialismo académico; Sociología africana.

\section{SOCIOLOGIE AFRICAINE: DU GÉNITIF DE L'OBJET AU GÉNITIF DU SUJET}

Résumé: Basé sur une discussion bibliographique et utilisant des critères historiques, ce texte propose une réflexion sur la sociologie africaine, prenant en compte le processus de formation, de développement, de professionnalisation et d'affirmation de cette science sociale en Afrique. Met en évidence trois perspectives pour l'étude et l'enseignement de la sociologie africaine et souligne le rôle de la sociologie africaine dans la pratique des sociologues africains et des professionnels impliqués dans le processus d'enseignement et d'apprentissage de la sociologie en Afrique, pour atténuer les effets de la dépendance académique et résister à l'eurocentrisme et à l'impérialisme académique de la géopolitique actuelle de la production de connaissances.

Mots-clés: Afrique; Dépendance académique; Géopolitique de la connaissance; Impérialisme académique; Sociologie africaine.

\section{INTRODUÇÃO}

A trajectória histórica da sociologia revela que esta ciência social surgiu, com esta designação, num contexto ocidental e, posteriormente, rumou para contextos não ocidentais. Esta trajectória faz dela uma ciência ocidental que, com o tempo e por vários factores envolvidos, passou a ser praticada fora do Ocidente. Primeiramente, por cientistas sociais ocidentais e, posteriormente, por cientistas sociais autóctones de lugares não ocidentais. É, neste contexto, de migração de pessoas, de ideias e de conhecimentos sociológicos que se pode falar do início da prática da sociologia em África. 
Note-se que não se está a dizer que os africanos esperaram pela sociologia, para pensarem o social. O pensamento social africano antecedeu o pensamento sociológico africano (VENÂNCIO, 2000). Em rigor, as reflexões sobre o mundo social são anteriores ao surgimento da sociologia, tanto em África, quanto em qualquer outro continente.

É possível reivindicar Ibn Khaldun e outros pensadores africanos, para demonstrar que o acto de pensar a respeito das sociedades humanas não é prática nova para as sociedades africanas (ALATAS, 2017). Contudo, o estudo sistemático das sociedades humanas é uma empreitada relativamente recente: data do fim do século XVIII e início do século XIX, na Europa (DORTIER, 2009). É neste sentido que se está a dizer que a sociologia migrou do Ocidente para África (AKIWOWO, 1990; TAMBA, 2014).

No presente texto, com base numa discussão bibliográfica e com recurso ao critério histórico, tecer-se-ão considerações a respeito da sociologia em África e, mais especificamente, da sociologia africana, enquanto área disciplinar e de ensino. Será objecto de reflexão o processo de formação, desenvolvimento, profissionalização e afirmação da sociologia em África.

Para sistematizar a abordagem, o texto será repartido em quatro momentos. Num primeiro, tecer-se-ão considerações a respeito do problema do status epistemológico da sociologia africana. No segundo, situar-se-á a sociologia africana no âmbito da investigação africana, tendo em atenção, por um lado, a sua relação com as outras ciências sociais e humanas que têm o continente africano como objecto de estudo e, por outro, os debates acerca do eurocentrismo e da geopolítica do conhecimento. Reservarse-á o terceiro momento, para tecer considerações a respeito da história da sociologia em África, com destaque para as tradições e correntes teóricas. Por fim, no quarto momento, tecer-se-ão considerações a respeito das problemáticas e temas da sociologia africana.

\section{O PROBLEMA DO STATUS EPISTEMOLÓGICO DA SOCIOLOGIA}

\section{AFRICANA}


O problema do status epistemológico da sociologia africana remete à problemática em torno das seguintes questões: Existe uma sociologia africana? Existe um pensamento sociológico africano? O que se deve entender por sociologia africana? Quão africana é a sociologia africana? O que é ser um sociólogo africano?

A expressão "sociologia africana" designa um caso genitivo. Pressupõe relação de posse. Indica que a sociologia em causa pertence ou está directamente relacionada com o continente africano. Trata-se, portanto, de regionalismos e genitivos que não são estranhos às ciências sociais.

A sociologia pode ser estudada por regiões e tradições nacionais. É no âmbito das regiões (ou áreas geográficas privilegiadas) que se estuda, por exemplo, a sociologia europeia, a asiática, a latino-americana etc. E é no âmbito das tradições sociológicas nacionais que se estuda a sociologia alemã, a italiana, a britânica, a brasileira, a angolana etc. Depreende-se que é, no âmbito das ciências regionais ou ciências com genitivo, que se fala de uma sociologia africana.

Nesta senda das ciências sociais com genitivo, Paulin Hountondji (2009, p. 121) faz a seguinte pergunta: "quão africanos são os chamados estudos africanos?". Exemplifica que "por história africana entende-se normalmente o discurso histórico sobre África, e não necessariamente um discurso histórico proveniente de África ou produzido por africanos". Constata-se aqui uma distinção entre genitivo objectivo e genitivo subjectivo, que ajuda a reflectir a respeito da problemática em torno do que se entende por sociologia africana: Quão africana é a sociologia africana? É uma sociologia de África ou uma sociologia sobre África? É uma sociologia produzida por africanos ou é indiferente à nacionalidade de quem a produz? Os estudos de um sociólogo europeu sobre as sociedades africanas deverão ser integrados na sociologia europeia ou na sociologia africana? Os estudos de um sociólogo africano sobre as sociedades europeias deverão ser integrados na sociologia europeia ou na sociologia africana?

Ao responder às perguntas acima formuladas, há duas posturas epistemológicas que se destacam na literatura sobre este assunto: uma pode ser extraída da análise de Hountondji sobre os estudos africanos e outra, da análise de Muanamosi Matumona sobre a sociologia africana. 
Com base em Hountondji (2009), por "sociologia africana", pode-se entender, mutati mutandis, "o discurso sociológico sobre África, e não necessariamente um discurso sociológico proveniente de África ou produzido por africanos" (HOUNTONDJI, 2009: p. 121). Sobretudo, se se tiver em conta que Hountondji, na senda dos casos genitivos, é peremptório em dizer que

\begin{abstract}
a sociologia ou a antropologia africanas significam a sociologia ou antropologia de África enquanto genitivo objectivo, ou seja, um discurso sociológico ou antropológico sobre África e não uma tradição sociológica ou antropológica desenvolvida por africanos em África. (HOUNTONDJI, 2009: p. 121).
\end{abstract}

Esta postura epistemológica não é a adoptada por todos os estudiosos da sociologia africana. A título de exemplo, Muanamosi Matumona (2008), recorrendo ao debate sobre as teologias com genitivo (originadas pela teoria das teologias contextuais), define a sociologia africana, como uma "sociologia contextual", uma “sociologia com genitivo" (MATUMONA, 2008, p. 29-30).

Matumona (2008) situa a sociologia africana no genitivo do sujeito e do objecto: “é uma 'sociologia de sujeito e de objecto', já que é promovida pelos africanos e é dirigida para eles, concentrando-se no seu mundo - a África..." (MATUMONA, 2008, p. 30).

Para este autor, a sociologia africana é uma reflexão crítica que "observa escrupulosamente os princípios epistemológicos exigidos pela filosofia das ciências (o rigor e a objectividade), tendo como objecto material o continente africano" (MATUMONA, 2008, p. 30). Daí que, para ele, a sociologia africana pode ser “encarada como uma 'sociologia regional' ou 'contextual': é elaborada pelos africanos e para os africanos, tendo como objecto principal de estudo o mundo [social] africano" (MATUMONA, 2008, p. 31).

Como se pode constatar, a postura epistemológica extraída de Hountondji e a extraída de Matumona têm em comum o objecto que atribuem à sociologia africana: $O$ mundo social africano. Porém, diferenciam-se quanto aos praticantes da sociologia africana. Em Matumona, a sociologia africana "é promovida pelos africanos e é dirigida para eles" ou, noutros termos, "é elaborada pelos africanos e para os africanos"; ao passo que, na perspectiva extraída de Hountondji, a sociologia africana é "um discurso sociológico sobre África e não uma tradição sociológica [...] desenvolvida por africanos 
em África"; ou, mutati mutandis, "o discurso sociológico sobre África, e não necessariamente um discurso sociológico proveniente de África ou produzido por africanos".

Para além destas duas posturas epistemológicas com que se pode proceder ao estudo da sociologia africana, é possível destacar uma terceira. Consiste em conciliar as duas posturas apresentadas: fazer da sociologia africana uma sociologia que constrói pontes e não uma sociologia que derruba pontes e ergue muros. Uma sociologia que não recaia na "etnossociologia" (no sentido pejorativo e depreciativo em que Hountondji usa a expressão "etnofilosofia") e nem na "extraversão"2 ou na "mente captiva"3. Uma sociologia que, nos dizeres de Hountondji, lida com "a recepção africana das tradições de investigação ocidentais e leva os académicos africanos a assumir as suas responsabilidades intelectuais próprias" (HOUNTONDJI, 2009, p. 124). Este alerta impõe tarefas e directrizes para a sociologia africana. Estende-se a todas as ciências sociais africanas e é reiterado por vários académicos africanos e afrodiaspóricos. A título de exemplo, Jean-Marc Ela ${ }^{4}$, Carlos Cardoso ${ }^{5}$ e Kabengele Munanga ${ }^{6}$.

Outro ponto em comum entre as duas posturas epistemológicas (Hountondji e Matumona) é o facto de ambas reconhecerem a sociologia africana como um campo de

\footnotetext{
2 A noção de "extraversão" (ou "extroversão") é oriunda da psicologia. Foi apropriada por Hountondji para se referir a uma tendência dos investigadores africanos que consiste em escrever para os seus colegas ocidentais e investigarem os temas que interessam o Ocidente.

\begin{abstract}
${ }^{3}$ A noção de "mente captiva" (captive mind) é proposta por Syed Hussein Alatas (1972). Refere-se a uma tendência dos intelectuais do sul epistemológico em relação às ciências sociais e humanas ocidentais. Uma "mente captiva" é a mente acrítica e imitativa, dominada por uma fonte externa (neste caso, as ciências sociais e humanas ocidentais), cujas práticas científicas (seleção de problemas, conceptualização, análise, generalização, descrição, explicação, interpretação, etc.) que imita acriticamente.
\end{abstract}

${ }^{4}$ A respeito do crise da racionalidade cientítica, Jean-Marc Ela postula que a participação dos investigadores africanos nesse debate "não consiste na africanização do saber ocidental" e que "a questão a formular deve incidir sobre a responsabilidade e o papel dos investigadores africanos na reinvenção da ciência" (ELA, 2015a, p. 104).

${ }^{5}$ Para Carlos Cardoso, "não se trata de inventar uma outra ciência para a África, mas de instituir uma outra prática científica... uma ruptura epistemológica não significa fechamento e autarcia estéreis do pensamento, mas reivindicação de um outro ponto de partida e por um outro sujeito que assume uma alternativa" (CARDOSO, 2012, p. 127-128).

${ }^{6}$ Referindo-se à antropologia africana, Munanga, faz a seguinte pergunta: "Como é que se pode africanizar e tornar fundamentalmente africana uma ciência fundamentalmente ocidental?" (MUNANGA, 1983, p. 157). Este reparo é extensivo a muitas outras ciências sociais que estiveram ao serviço da colonização. 
estudo que reflecte sobre os problemas sociais e as realidades sociais africanas. ${ }^{7} \mathrm{Na}$ perspectiva de Matumona, a sociologia africana tem "como objecto material o continente africano" ou "o mundo [social] africano". Quanto a Hountondji, nas suas críticas à tendência para a extraversão das investigações africanas, constata-se a necessidade de uma sociologia que vá "ao encontro das necessidades tanto intelectuais como materiais das sociedades africanas”. Hountondji realça que os investigadores africanos, na maioria das vezes, tendem "a investigar temas que são do interesse, antes de mais, de um público ocidental" e que a maioria dos seus artigos "é publicada em revistas científicas sediadas fora de África, destinando-se, portanto, a leitores nãoafricanos" (HOUNTONDJI, 2009, p. 127-128).

É neste sentido que Hountondji considera a investigação científica africana como uma actividade científica extravertida, isto é, “orientada para o exterior, destinada a ir ao encontro das necessidades teóricas dos parceiros ocidentais e a responder às perguntas por eles colocadas" (HOUNTONDJI, 2009, p. 127-128).

O diagnóstico de Hountondji conclui que "os académicos africanos têm participado, até agora, numa discussão vertical com os seus parceiros ocidentais, ao invés de entabularem discussões horizontais com outros académicos africanos" (HOUNTONDJI, 2009, p. 128). Neste diagnóstico, constatam-se vários assuntos que estão em pauta nos debates contemporâneos em torno do eurocentrismo e da geopolítica da produção do conhecimento (existência de relações hierárquicas, dependência académica, imperialismo académico, etc.). ${ }^{8}$

Quanto ao que expôs no seu diagnóstico, Hountondji admite que o panorama apresentado é de muitos anos atrás e que se registaram mudanças. Enfatiza a existência em África de comunidades científicas regionais, sub-regionais e nacionais, a existência de universidades e centros de investigação de excelência, a existência de cientistas e investigadores de excelência e com carreiras muito bem sucedidas. Todavia, alerta que estas mudanças e progressos ainda estão longe de atingir um objectivo fundamental: um processo autónomo e auto-confiante de produção de conhecimento e de capitalização que permita aos cientistas e investigadores africanos responder às suas próprias questões

\footnotetext{
${ }^{7}$ Neste quesito, convém que a sociologia africana esteja alerta quanto às "formas africanas de autoinscrição" criticada por Achille Mbembe (2001).

${ }^{8}$ Encontra-se uma discussão sistematizada das noções de "imperialismo académico" e "dependência académica" em Syed Farid Alatas (2003). Esta noções também foram discutidas, anteriormente, nas décadas de 1960 e 1970 e, mais recentemente, na década de 2000, por Syed Hussein Alatas (2000).
} 
e ir ao encontro das necessidades tanto intelectuais como materiais das sociedades africanas. Segundo este autor, o primeiro passo para alcançar este objectivo "seria talvez formular 'problemáticas' originais, conjuntos originais de problemas estribados numa sólida apropriação do legado intelectual internacional e profundamente enraizados na experiência africana" (HOUNTONDJI, 2009, p. 128). Eis aí alguns desafios e directrizes para a sociologia africana.

Com relação a este assunto, José Carlos Venâncio (2000) realça que

Há muito que se tornou consensual entre os cientistas sociais que o estudo de África, enquanto um todo, ou doutra realidade equivalente, leva ao desenvolvimento de metodologias e conceitos próprios, que não só vêm contribuir para um melhor conhecimento da realidade em estudo, como enriquecem igualmente o corpo teórico das ciências onde tais abordagens se filiam, tornando-o mais universal. (VENÂNCIO, 2000, p. 26).

Por sua vez, Carlos Cardoso (2012) postula que "ao mesmo tempo que se reclama um lugar para as ciências sociais praticadas em África, devemos voltar os olhares para as condições de produção científica existentes no continente", pois, "uma coisa é reconhecer a indispensabilidade de uma epistemologia alternativa e outra é criar as condições da produção da mesma, sendo, por isso, a questão maior a de saber como produzir esta epistemologia" (CARDOSO, 2012, p. 125-126). O autor continua, sublinhando que a produção de uma epistemologia alternativa, tão apregoada pelos cientistas sociais do sul, só ganhará sentido, "quando for capaz de se integrar numa 'episteme' socialmente reconhecida e consequentemente pertinente, que seja portadora de um potencial de transformação social susceptível de se traduzir num projecto emancipador" (CARDOSO, 2012, p. 125-126). Sublinha igualmente que reconhecer a falta de condições de produção de uma epistemologia alternativa é "uma condição sine qua non para o início da luta pela sua efectivação" (CARDOSO, 2012, p. 126).

Ainda com relação ao problema do status epistemológico da sociologia africana, Akinsola Akiwowo (1980), no seu relatório sobre o estado da sociologia em África, realça, por um lado, que "se deve admitir que é difícil afirmar categoricamente se existe ou já existiu alguma sociologia distintamente africana e que esquema paradigmático ela possui" e, por outro lado, preconiza que as primeiras "tentativas de caracterizar a sociologia africana foram empreendidas por Pierre van der Berghe, pelo 
professor [Herbert] Vilakazi e por Georges Balandier, em vários momentos e lugares [textos]". 9 (AKIWOWO, 1980, p. 4).

Destes três autores apontados por Akiwowo, Balandier foi francês; van der Berghe nasceu no ex-Congo Belga, mas os seus pais eram belgas; e Vilakazi era sulafricano. Quem pode ser reivindicado como "sociólogo africano"? Todos? Van der Berghe e Vilakazi? Ou Vilakazi apenas?

A reposta à pergunta "Quem deve ser considerado sociólogo africano?" depende do critério que se adopta para especificar o que se quer dizer com a designação "sociólogo africano": ter nacionalidade africana; ter África como objecto de estudo, independentemente da nacionalidade etc.

Historicamente, os africanistas europeus foram os primeiros a estudar as sociedades africanas, no âmbito das ciências sociais. Os africanistas africanos surgiram, posteriormente, como aprendizes dos africanistas europeus. Por exemplo, dentre os africanistas europeus, Georges Balandier e Jean Copans foram dos primeiros a estudar sociológica e antropologicamente as sociedades africanas. Podem ou não ser considerados "sociólogos africanos"? E os seus estudos podem ou não ser integrados no corpus da sociologia africana? Note-se, por exemplo, que Balandier é considerado um “iniciador incontestável da sociologia no Senegal”. (TAMBA, 2014, p. 11).

Destacam-se também os casos de Pierre Bourdieu e de John Rex. A sociedade cabila, na Argélia, foi objecto de estudo das primeiras pesquisas de Bourdieu. No seu livro Sociologia da Argélia (publicado em 1958), Bourdieu analisa a organização social da sociedade cabila e o impacto do sistema colonial nas suas estruturas e desculturação. Este estudo pode ou não integrar o corpus da sociologia africana?

Quanto a Rex, foi um sociólogo britânico, nascido na África do Sul. Foi dos primeiros a estudar sociologicamente as relações raciais e étnicas, na África do Sul. Os seus estudos podem ou não integrar o corpus da sociologia africana? Ele é um sociólogo africano?

Pelo exposto, embora discutível, é indubitável que os sociólogos europeus que estudaram as sociedades africanas podem ser apontados como predecessores dos

\footnotetext{
9 "Before starting on the Report it must be admitted that it is difficult to state categorically whether any distinctively African sociology exists, or ever existed, and what paradigmatic scheme it possesses. [...]. Attempts to characterize African sociology have been undertaken by Pierre van der Berghe, Professor Vilakazi and Georges Balandier, at various times and places".
} 
sociólogos de nacionalidades africanas que estudam/estudaram as sociedades africanas.

Sobre este assunto, Tamba preconiza que "a sociologia africana moderna nasceu durante o período colonial (de 1945 a 1960)" e que "foi iniciada por pesquisadores ocidentais". ${ }^{10}$ (TAMBA, 2014, p. 15).

Eis a forma como, em outros termos, Akiwowo colocou esta tese:

... o sociólogo europeu da sociedade africana é, intelectualmente, o predecessor do africano contemporâneo que foi treinado como sociólogo nas instituições de ensino europeias ou americanas e que, agora, faz das sociedades africanas seus objectos de estudo. ${ }^{11}$ (AKIWOWO, 1980, p. 5).

É inegável que a situação colonial ${ }^{12}$ influenciou e marcou a prática da sociologia em África, profissional, académica e institucionalmente. A respeito deste assunto, Akiwowo diz o seguinte:

A sociologia é uma daquelas invenções da civilização ocidental que foi introduzida em África, durante a época colonial. Inicialmente, ela não encontrou lugar nos currículos das faculdades e instituições similares que estavam a ser introduzidas em África [...]. Em vez disso, fazia parte das habilidades que o administrador colonial, sobretudo nos territórios britânicos, cultivava e aplicava durante o seu período de serviço colonial. [...]. Não foi até ao início dos anos sessenta deste século [i.e, do século XX] que a sociologia se tornou parte do programa de ensino superior em expansão [...] nalguns países. ${ }^{13}$ (AKIWOWO, 1980, p. 8).

\footnotetext{
10 "La sociologie africaine moderne est née durant la période de la décolonisation (1945-1960). Elle a été initiée par les chercheurs occidentaux.".

11 “... the European sociologist of African society is, intellectually, the predecessor of the contemporary African who has been trained as a sociologist in European or American institutions of learning and who now makes African societies his objects of study".

12 A noção de "situação colonial" foi proposta por Georges Balandier. Refere-se à situação de "dominação imposta por uma minoria estrangeira, racial (ou étnica) e culturalmente diferente, em nome de uma superioridade racial (ou étnica) e cultural afirmada dogmaticamente, sobre uma minoria autóctone materialmente inferior". Esta situação conduz a entroncamento de civilizações heterogéneas (civilização maquinista e cristã vs. civilização não-maquinista e não cristã) e recorre a um "conjunto de pseudojustificações e pensamentos estereotipados, etc., para preservar a dominação" (BALANDIER, 2014, p. 45-46).

13 "Sociology is one of those inventions of western civilization that was introduced into Africa during the colonial epoch. It did not, at the start, find its place in the curricula of the university colleges and similar institutions that were being introduced in into Africa [...]. Rather it was part of the skills which the colonial administrator, particularly in the British territories, was to cultivate and to apply during his period of colonial service. [...]. It was not until in the early sixties of this century that sociology became part of the expanding higher education programme [...] in some countries".
} 
A longa citação em epígrafe demonstra a necessidade de rever as cosmovisões e as formas de pensamentos que estiveram na base do surgimento das ciências sociais ocidentais (sobretudo, no caso da antropologia). Pois, estas ciências sociais, no seu surgimento, veiculavam (e, nalguns casos ainda veiculam) uma cosmovisão eurocêntrica que considerou, como universal, o que é típico da Europa e legitimou preconceitos étnicos e raciais, bem como várias formas de opressão (Mlambo, 2006; Connell, 2012).

Eis o que Carlos Cardoso diz a respeito disto:

as ciências sociais, tal como foram concebidas no Ocidente e introduzidas em África, rejeitaram a interpretação da África enquanto continente civilizado, sobretudo a de um sujeito capaz de pensamento autónomo. A construção do conceito e sua aplicação no continente estavam impregnadas do discurso racial colonial de 'alteridade'. (CARDOSO, 2012, p. 128).

A terminar este momento sobre o status epistemológico da sociologia africana, enfatiza-se que, enquanto campo de estudo, a sociologia africana, segundo Matumona, está "integrada no universo da sociologia geral e na linha das 'sociologias particulares"; é uma sociologia que "adere a todos os princípios gerais da sociologia" e, por este motivo, "é lógico que seja apontada como uma autêntica epistemologia", pois, é uma "reflexão crítica" e "não se trata de uma mera prática que deve relegar para segundo plano as preocupações epistemológicas”. (MATUMONA, 2008, p. 28-29).

A respeito deste assunto, Valentin Nga Ndongo, sociólogo camaronês que dirige a colecção Sociologie africaine da editora L'Harmattan, diz o seguinte, na nota de apresentação da colecção ${ }^{14}$ :

... se é chegada a hora de uma sociologia africana, resta que ela ainda deve convencer pela credibilidade dos seus paradigmas, pela solidez dos seus métodos, bem como pela especificidade das suas problemáticas, da sua vocação e das suas questões política e geopolítica no mundo actual. ${ }^{15}$

\section{Acrescenta que}

\footnotetext{
${ }^{14}$ A nota de apresentação da colecção Sociologie africaine é de 2010. Mas foi extraída do livro La sociologie camerounaise. Un demi-siècle de lente mais dynamique construction, da autoria de Valentin Nga Ndongo, publicado em 2017.

15 "Mais si le temps de la sociologie africaine s'impose, il reste que celle-ci doit encore convaincre de la crédibilité de ses paradigmes, de la solidité de ses méthodes ainsi que de la spécificité de ses problématiques, de sa vocation et de ses enjeux politiques et géopolitiques dans le monde d'aujourd'hui".
} 
A sociologia africana deve também demonstrar que não é uma gíria sociológica, tropicalizada, periférica, apoiada por alguma pretensão racial absurda, mas que é uma sociologia tout court, uma sociologia prometéica, isto é, uma apropriação por africanos, de um conhecimento que, tendo servido por muito tempo à sua opressão, deve, a partir de então, constituir o instrumento por excelência da sua libertação. ${ }^{16}$

Tendo como objecto de análise a realidade social africana, a sociologia africana, ao aderir aos princípios do conhecimento científico ocidental, convém que o faça de forma crítica. São os problemas sociais e as realidades sociais africanas que fornecem elementos para uma reflexão sociológica afrocentrada.

A sociologia africana é, portanto, uma "sociologia das sociedades africanas"17 e, como tal, adopta análises inter-, trans- e multidisciplinar dessas sociedades, pois, estas possuem múltiplas faces (MOURÃO, 1995/1996; HEIMER, 2001; MACAMO, 2002). Depreende-se daqui que a sociologia africana se relaciona com as diversas disciplinas que têm o continente africano como objecto de estudo, por intermédio de uma atitude inter-, trans- e multidisciplinar, pois, tal como preconizam Carlos Pimenta e Víctor Kajibanga, "estudar África é interpretar, compreender e sentir uma certa sociedade, no tempo e no espaço, na plenitude da sua complexidade" (PIMENTA \& KAJIBANGA, 2011, p. 1). Portanto, a prática de uma sociologia africana pressupõe que esta se relacione com as outras ciências sociais africanas, ou seja, que têm África como objecto de estudo.

\section{A SOCIOLOGIA AFRICANA NO ÂMBITO DA INVESTIGAÇÃO AFRICANA}

A sociologia africana não caminha só. Estabelece relações com a investigação africana das outras áreas das ciências sociais e humanas. Por exemplo, está fortemente

\footnotetext{
16 "La sociologie africaine doit également démontrer qu'elle n'est pas une sociologie argotique, tropicalisée, périphérisée, adossée à quelque absurde revendication raciale mais qu'elle est une sociologie tout court, une sociologie prométhéenne, c'est-à-dire une appropriation, par les Africains, d'un savoir qui, ayant longtemps servi à leur oppression, doit désormais constituer l'instrument par excellence de leur libération.".

${ }^{17}$ A respeito da constituição de uma sociologia das sociedades africanas, Elísio Macamo (2002) defende que "uma sociologia das sociedades africanas não pode ser essencialista no sentido de estudar apenas o que é definido a priori como sendo eternamente africano, mas sim processual na medida em que analisa as transformações sociais que ocorrem naquilo que pode ser considerado um espaço e tempo africano" (MACAMO, 2002, p. 7).
} 
relacionada com a filosofia africana, teologia africana, história africana e com o pensamento social africano em geral. Grosso modo, dialoga com as outras ciências sociais que têm África como objecto de estudo e que, facilmente, podem ser agrupadas numa área de estudo mais ampla sobre o continente africano: os chamados "estudos africanos"18 (HOUNTONDJI, 2009; PIMENTA \& KAJIBANGA, 2011).

Existe uma inter-relação entre estas ciências e há boas razões para que assim seja. Recorrendo a Hountondji (2009), pode-se tomar o caso da história africana e da sociologia africana como exemplo. Entre ambas, existe uma "complementaridade objectiva", pois, se, por um lado, "a situação presente de qualquer sociedade decorre, directa ou indirectamente, do respectivo passado", por outro lado, "um bom conhecimento do presente e da lógica dos acontecimentos na vida actual pode oferecer pontos de vista úteis para compreender o passado" (HOUNTONDJI, 2009, p. 120).

A história africana produzida por africanos tem contribuído para a reescrita e releitura de África, bem como para o despertar da consciência histórica africana que é, em si, uma ferramenta metodológica e epistemológica fundamental para a sociologia africana e para a investigação africana em geral (DIOP \& DIENG, 2014; MAKGOBA, 2016).

A investigação africana, sobretudo nos países anglófonos e francófonos, tem produzido obras de referência de autores africanos e africanistas, no domínio das ciências sociais e humanas, a partir de um olhar de dentro. Estas obras têm contribuído para a compreensão e reinterpretação do continente africano, bem como para a construção do que Kajibanga designa por "epistemologia dos saberes endógenos" (KAJIBANGA, 2008b). Tal epistemologia tem permitido a substituição de um tipo de conhecimento em que o africano é apenas objecto por formas de compreender o mundo social africano produzidas por africanos (HOUNTOUNDJI, 2009; MARTINS et al, 2019; MERLEN, 2020).

No entender de Kajibanga, os principais debates que contribuíram para a construção da "epistemologia dos saberes endógenos" surgiram "no âmbito da ciência histórica, da filosofia, da literatura teórica (ensaística), da crítica literária e da sociologia

\footnotetext{
${ }^{18}$ Hountondji (2009) propõe uma definição muito ampla de "estudos africanos" a que recorremos. Ei-la: "Quando falamos de estudos africanos, normalmente estamos a referir-nos não apenas a uma disciplina, mas a todo um leque de disciplinas cujo objecto de estudo é África. Entre estas incluem-se, frequentemente, disciplinas como a 'história africana', 'antropologia e sociologia africanas', 'linguística africana', 'política africana', 'filosofia africana', etc.” (HOUNTONDJI, 2009, p. 119).
} 
africanas" (KAJIBANGA, 2008b, p. 7-8). Este autor assevera que três acontecimentos seminais propiciaram a ruptura epistemológica em relação ao paradigma dos estudos coloniais, "que assentavam, regra geral, numa visão exógena e exótica duma 'realidade africana' distorcida" (KAJIBANGA, 2008b, p. 8). Os três acontecimentos são: (i) a criação da revista Présence Africaine (em 1947, em Paris); (ii) o surgimento do Centro de Estudos Africanos, em Lisboa; e (iii) a publicação do livro Nations Nègres et Culture, de Cheikh Anta Diop, em 1954.

Na esteira de Venâncio (2000), podemos acrescentar um outro acontecimento: o $1^{\circ}$ Congresso dos Escritores e Artistas Negros, realizado em 1956, em Paris. Este congresso, no entender deste autor, foi um "momento marcante para o desenvolvimento do pensamento social africano" e "muitas intervenções tiveram recortes abertamente sociológicos" (VENÂNCIO, 2000, p. 27).

Ao longo do século passado, vários debates estruturaram a configuração das grandes tendências das ciências sociais e humanas em África. Kajibanga destaca quatro: (i) o debate sobre a existência ou não de uma filosofia africana; (ii) o debate sobre drumulogia; (iii) o debate sobre a indigenização da sociologia e (iv) o debate no âmbito da teologia africana que originou as "Ciências Sociais e Humanas da Reconstrução": Teologia da Reconstrução, Teologia Africana da Reconstrução e Sociologia da Reconstrução. ${ }^{19}$ (KAJIBANGA, 2008b, p. 9-10).

Nestes debates, encontram-se contribuições de nomes sonantes da investigação africana de antanho e contemporânea que enriquecem a produção intelectual e reforçam a constituição do pensamento social e sociológico africano (DEVÉS-VALDÉS, 2008; KAJIBANGA, 2008b). Tais debates, decorrentes no e sobre o continente africano, a partir de uma visão endógena, constituem-se em espaços de alteridade e de reflexão crítica a respeito da racionalidade científica e dos problemas sociais do continente. Pois, como realça Ela, a ciência "possui os seus actores e os seus produtores, as suas instituições e as suas redes, os seus ritos e os seus templos, as suas revistas e as suas publicações", bem como "o seu espírito, os seus princípios e os seus métodos, as suas teorias e os seus paradigmas" (ELA, 2015a, p. 11). Tais debates e algumas iniciativas organizativas atribuem à investigação africana estes elementos, embora ainda existam

\footnotetext{
${ }^{19}$ No contexto angolano, o debate a respeito da filosofia africana encontrou litigantes em Pedro Miguel, Luís Kandjimbo e Muanamosi Matumona. Por sua vez, a "Sociologia das mutações" encontrou praticante em Muanamosi Matumona (KAJIBANGA, 2008b; KAJIBANGA, 2015).
} 
vários obstáculos colocados à produção africana do conhecimento científico (CARDOSO, 2012; ELA, 2015a; ELA, 2015b; ELA, 2015b).

A África francófona e anglófona são presenças constantes nestes debates sobre África e sobre as ciências sociais em contexto africano. Facto que contrasta com a pouca presença da África lusófona (MATUMONA, 2008). A título de exemplo, para o caso do debate sobre a filosofia africana, Kajibanga relata que, "nos países africanos de língua oficial portuguesa (incluindo na antiga 'Metrópole'), só em finais da década de 1980 e início da década de 1990, se começou a falar publicamente (e nas cátedras) sobre a filosofia africana." (KAJIBANGA, 2015, p. 24-25).

Matumona enfatiza o lusotropicalismo e o sistema educativo (herdeiro da tradição da administração colonial portuguesa) como causas do "atraso" dos estudiosos da África lusófona. ${ }^{20}$ Todavia, admite os avanços da África lusófona em direcção aos debates sobre África e defende que, ao marcar presença nestes debates, a África lusófona deve "apresentar novidades" e evitar ser "uma mera 'caixa de ressonância', sobretudo dos francófonos e anglófonos" (MATUMONA, 2008, p. 23).

Estas diferenças internas (anglofonia, francofonia e lusofonia) da sociologia africana são fundamentais para a compreensão da história da sociologia em África, das tradições nacionais, das correntes teóricas e dos problemas sociais estudados.

\section{SOCIOLOGIA AFRICANA: HISTÓRIA, TRADIÇÕES E CORRENTES TEÓRICAS}

A sociologia africana é um caso genitivo que remete a uma sociologia regional, constituída por várias “sociologias nacionais". Daí que tratar da sua história implica ter em atenção as peculiaridades de cada uma das tradições sociológicas nacionais que a compõem.

O que a maioria das "sociologias nacionais" dos países africanos tem em comum é o facto de a sociologia, nos seus territórios, ter sido inicialmente praticada por sociólogos europeus e apenas, posteriormente, por sociólogos autóctones de países africanos. Quanto a estes, as primeiras gerações foram compostas por sociólogos

20 Eis as palavras de Matumona: "Quando se fala em herança colonial, no caso da educação, deve compreender-se que se trata de uma situação em que as escolas estiveram ao serviço da colonização. Os letrados africanos formados pelo sistema serviam de intermediários da administração colonial e foram desenraizados das suas origens, em nome de uma pretensa civilização a que se chamou 'assimilação'. " (MATUMONA, 2008, p. 22). 
formados nas então metrópoles (alguns, durante o período colonial e outros, no período pós-colonial) e, por sua vez, as gerações posteriores (sobretudo aquelas do período póscolonial) são compostas simultaneamente por sociólogos formados localmente e os formados nos países europeus.

A sociologia africana e os seus praticantes herdaram um quadro teóricoconceptual e metodológico ocidental de que, aos poucos, alguns se foram libertando, por causas relacionadas com a ineficácia destes quadros teórico-conceptuais e metodológicos, para o estudo das realidades sociais africanas, bem como por questões relacionadas com o carácter eurocêntrico destes quadros teórico-conceptuais e metodológicos.

Quanto às correntes teóricas, pode-se dizer que as principais correntes teóricas da sociologia clássica e contemporânea encontram praticantes no âmbito da sociologia africana. Entretanto, há que sublinhar que alguns sociólogos africanos aceitam, como universais, os postulados destas correntes teóricas e as reproduzem e as aplicam fielmente à análise das sociedades africanas, ao passo que outros provincializam estas correntes teóricas e as confrontam com a realidade social africana, para testar as suas validades, na análise das sociedades africanas. ${ }^{21}$

Estudar a sociologia africana impõe, dentre outras coisas, a necessidade de estudar as particularidades da história da sociologia em África, da sua institucionalização, da sua profisssionalização e dos principais temas estudados. Levando em consideração estes elementos e com base na literatura consultada, pode-se destacar três estratégias possíveis para estudar a sociologia africana.

Uma dessas estratégias consiste em agrupar as diferentes "sociologias nacionais" que compõem a sociologia africana, tendo em atenção o factor linguístico. Com base neste critério, ter-se-á, por exemplo, a escola anglófona de sociologia africana, a escola francófona de sociologia africana, a escola lusófona de sociologia africana e escola magrebina de sociologia africana. A título de exemplo, tem-se a análise de José Gonçalves (1992) e de Carlos Cardoso (2017) sobre as ciências sociais

\footnotetext{
${ }^{21}$ Akiwowo aponta esta dependência às teorias e categorias conceptuais desenvolvidas no Ocidente como obstáculo ao desenvolvimento de melhores paradigmas para a análise das sociedades africanas e apela à necessidade de desenvolver epistemologias alternativas, para reduzir a dependência académica e resistir ao imperialismo académico (AKIWOWO, 1980, p. 6-7).
} 
na África lusófona e a análise que Tayeb Chenntouf (2006) faz sobre a sociologia no Magrebe.

Outra estratégia consiste em estudar, separadamente, as diferentes "sociologias nacionais" que compõem a sociologia africana. Com base neste critério, tratar-se-ia da sociologia africana, a partir da análise de algumas tradições sociológicas nacionais seleccionadas, sob o auspício de determinados factores. A título de exemplo, temos o caso de Akiwowo que, no seu relatório sobre o estado da sociologia em África, tratou da situação da "sociologia nacional" de treze países seleccionados (AKIWOWO, 1980).

Por sua vez, uma terceira estratégia consiste em estudar as diferentes "sociologias nacionais" que compõem a sociologia africana, tendo em atenção a divisão regional de África. ${ }^{22}$ Com base neste critério, por exemplo, tratar-se-ia da sociologia na África Mediterrânea e na África Subsaariana. Ou ainda, com base nas cinco macrorregiões de África, tratar-se-ia da sociologia na África do Norte/Setentrional, na África Austral/Meridional, na África Ocidental, na África Oriental e na África Central. A título de exemplo, tem-se o estudo sobre a sociologia na África Central de Valentin Nga Ndongo (2006) e o estudo sobre as ciências sociais na África do Norte de Roland Waast, Claire Richard-Waast e Pier L. Rossi (2010).

Quanto à história da sociologia em África, no cômputo geral, pode ser repartida em três períodos: (i) o período pré-colonial; (ii) o período colonial; e (iii) o período póscolonial (TAMBA, 2014). Porém, esta periodização e as suas delimitações temporais devem levar em consideração as peculiaridades históricas de cada uma das "sociologias nacionais" que compõem a sociologia africana.

Actualmente, a sociologia africana tem os seus actores e produtores (cientistas sociais a título individual e reunidos em associações científicas e profissionais); tem as suas instituições (associações científicas, centros de ensino e investigação); tem as suas redes de investigação (como o CODESRIA - Conselho para o Desenvolvimento da Pesquisa em Ciências Sociais em África); tem as suas revistas e outras publicações (como a Revista Africana de Sociologia e as revistas de sociologia dos respectivos países africanos). Estes elementos ainda não estão com as quantidades e qualidades

\footnotetext{
${ }^{22}$ A divisão regional de África leva em consideração o deserto do Saara como um marco divisor. Daí ser possível dividir África em duas partes: a África Saariana (conhecida também como Islâmica e "África branca”) e a África Subsaariana (ou "África negra”) (VENÂNCIO, 2000; GONÇALVES, 2016).
} 
desejadas, porém, têm registado avanços consideráveis, nalguns aspectos e recuos, noutros (CARDOSO, 2012; ELA, 2015c).

Akiwowo destaca o papel da UNESCO na institucionalização e profissionalização da sociologia e doutras ciências sociais em África (AKIWOWO, 1980). As condições da prática das ciências sociais variam de país para país. A respeito deste assunto, Cardoso (2012) apresenta um diagnóstico nada abonatório a respeito da prática das ciências sociais em África: condições precárias para a prática das ciências sociais, na maioria dos casos; constrangimentos significativos que afectam o seu cabal desenvolvimento; pouco investimento nas faculdades de letras e ciências sociais e humanas; o apetrechamento das salas de estudo (computadores, acesso à Internet, etc.) continua a ser um luxo a que muitas universidades não se podem dar; etc. (CARDOSO, 2012, p. 134-135).

No período a seguir às independências africanas, a maioria das ciências sociais foram consideradas ciências "subversivas" em muitos países africanos: nos casos em que não foram banidas dos curricula universitários, foram objectos de fortes controlos e censuras (KAJIBANGA, 2008a; TAMBA, 2014). Contemporaneamente, Cardoso (2012) realça que, com as mudanças registadas no ambiente sociopolítico, houve melhorias nas últimas três décadas: "a liberdade de expressão é hoje uma realidade palpável na maior parte dos países africanos"; "as universidades gozam de uma relativa autonomia e, quanto à liberdade académica, "apesar de ainda conhecer restrições pontuais, faz parte da realidade vivida na maior parte das instituições de ensino superior" (CARDOSO, 2012, p. 136-137).

Entretanto, apesar dessas "melhorias", Cardoso (2012) acentua as ainda existentes restrições ao livre exercício do métier do cientista social: restrições financeiras impostas pela ausência de um engajamento do Estado para com as ciências sociais; ainda existe desconfiança em relação às ciências sociais, pelo facto de serem capazes de questionar o poder instituído; as ciências sociais são alvo de um tratamento depreciativo motivado pelo argumento de que não contribuem para o desenvolvimento socioeconómico do país e "constituem um luxo para países que se debatem com insuficiência de recursos financeiros, como é o caso de muitos países africanos." (CARDOSO, 2012, p. 137). 
Refutando a tese da inutilidade das ciências sociais, Cardoso (2012), aponta as quatro razões dadas por Shula Marks, para justificar o ensino das ciências sociais nas universidades sul-africanas, convicto de que estas razões "podem ser generalizadas para o resto do continente não só no que toca ao ensino em si, mas igualmente no que diz respeito à própria prática das ciências sociais" (CARDOSO, 2012, p. 137-138). Eis as razões:

A primeira é para refutar os mitos criados pela conceptualização ocidental da África; a segunda, para reinterpretar a história em África de uma maneira nãoessencializante; a terceira, para estudar as ciências sociais de uma maneira que não oponha as ciências naturais às ciências sociais como se fossem diametralmente opostas; e a quarta, enfim, para nos darmos conta que o estudo da África desestabilizou os instrumentos conceptuais ocidentais e apelou à re-conceptualização da pesquisa, tanto africana como ocidental, no domínio das ciências sociais.

A estas quatro razões, Cardoso (2012) acrescenta uma quinta razão. Esta razão consiste na necessidade de tornar as ciências sociais socialmente relevantes, fazendo delas um "instrumento de transformação das sociedades africanas" e partes integrantes de um "projecto emancipador", firmado como uma "uma epistemologia alternativa" (CARDOSO, 2012, p. 138). Contudo, com relação aos apelos à criação de uma epistemologia alternativa, o autor revela que "muitas das iniciativas com vista à melhoria das condições de produção do conhecimento científico [...] continuam a estar ligadas ou são globalmente controladas pelo Norte" (CARDOSO, 2012, p. 138).

É o caso, por exemplo, da Iniciativa Think Tank (financiada pelo IDRC International Development Research Centre do Canadá e pelas fundações americanas William \& Flora Hewlett e Bill \& Melinda Gates) e o da Iniciativa África/EUA para o desenvolvimento do ensino superior em África (financiada pelo Departamento de Estado norte-americano).

Constatações como estas nutrem o afro-pessimismo e fazem crer que está tudo perdido para as ciências sociais em África. Contudo, Cardoso (2012) sublinha que “África não é redutível a calamidades e a epidemias"; que é necessário "ter uma visão mais realista de África, um continente antes de mais nada plural e cheio de contrastes"; e que "algumas condições económicas dão a esperança de que a situação pode melhorar" (CARDOSO, 2012, p. 139). 
No mesmo diapasão, Jimi Adesina (2012) diz o seguinte:

A lamentação e o pessimismo caracterizam grande parte das discussões sobre o estado das ciências sociais e humanidades em África. Há, sobretudo, referências ao carácter imperial da divisão global do trabalho na produção de conhecimento. A crise da fuga de cérebros e o estado em que se encontram as nossas faculdades, fragilizam, ao invés de reforçar, a geração mais nova de académicos africanos em redor dos quais se centram os nossos esforços (ADESINA, 2012, p. 195).

Quanto aos actores, produtores e instituições da sociologia africana, a escola francófona e a anglófona são as mais influentes ${ }^{23}$. A maioria das figuras de proa da sociologia africana ("clássica" e contemporânea) pertence a estas duas escolas. Eis algumas dessas figuras: Aguessy Honorat, Axelle Kabou, Jean-Marc Ela, Valentin Nga Ndongo, Moustapha Tamba (África francófona) e Akinade Olumuyiwa Sanda, A. Muyiwa Sanda, Akinsola Akiwowo, Bernard M. Magubane, Ifi Amadiume, Jimi O. Adesina, Oyeronke Oyewumi (África anglófona). Quanto à África lusófona, eis algumas figuras que se destacam: Carlos Cardoso, Carlos Serra, Cesaltina Abreu, Elísio Macamo, Patrício Langa, Maria Paula Meneses, Mário Pinto de Andrade, Paulo de Carvalho, Víctor Kajibanga.

A estes nomes, podem-se acrescentar outras figuras que se destacaram em outras ciências sociais africanas, independentemente das nacionalidades. Pois, a sociologia africana é devedora de debates sobre a condição africana tidos noutras ciências sociais. Eis alguns nomes a reter: Achille Mbembe, Ali A. Mazrui, Alphonse Elungu Pene Elungu, Alioune Diop, Aquino Bragança, Archie Mafeje, Brazão Mazula, Carlos Serrano, Cheikh Anta Diop, Elikia M'Bokolo, Fernando Mourão, Franz-Wilhelm Heimer, Joseph Ki-Zerbo, Kwame A. Appiah, Paulin Hountondji, Ruth First, Samir Amin, Severino Elias Ngoenha, Thandika Mkandawire, Théophile Obenga, Valentin Mudimbe.

No cômputo geral, é no pensamento social e sociológico destes académicos africanos e de outros não citados que se encontram os principais temas e problemáticas da sociologia africana.

\footnotetext{
${ }^{23}$ No entender de Matumona (2008), “a África lusófona apresenta-se como uma área pobre em termos de produção académica sobre a sociologia africana; isto, se formos a comparar o seu rendimento com os trabalhos dos autores francófonos e anglófonos, que deram largos passos nesta matéria". Porém, reconhece que "algo vai sendo feito" e que "os países africanos de língua oficial portuguesa poderão vir a ter uma palavra a dizer nesta matéria." (MATUMONA, 2008, p. 30).
} 


\section{PROBLEMÁTICAS E TEMAS DA SOCIOLOGIA AFRICANA}

A sociologia africana está imbuída de problemáticas. Nos pontos anteriores, realçaram-se problemas relacionados com a definição de "sociologia africana" e de "sociólogo africano". Uma das problemáticas que ocupa os defensores de uma sociologia africana, como campo de estudo, consiste na reflexão sobre as suas próprias práticas científicas: a necessidade de trilhar caminhos que levem em consideração a singularidade africana, sem ser essencialista, e reavaliar os diálogos com a ciência social ocidental.

Na década de 1980, Akinsolo Akiwowo galvanizou um debate sobre as indigenous sociologies que se repercutiu dentro e fora do continente, e intensificou a busca pela endogeneidade (AKIWOWO, 1989; AKIWOWO, 1990; AKIWOWO, 1998). Dentre os intervenientes neste debate, destacam-se: A. Muyiwa Sanda, Jimi O. Adesina, M. Akin Makinde, O. B. Lawuyi e Olufemi Taiwo (SANDA, 1988; LAWUYI \& TAIMO, 1990; MAKINDE, 1990; ADESINA, 2002).

Foi dito que a sociologia africana, inicialmente, herdou as temáticas da condição africana tratadas por sociólogos ocidentais, tais como, Georges Balandier, Jean Copans e Jean Ziegler. Actualmente, praticada por africanos, a sociologia das sociedades africanas acumulou um conjunto diferenciado de temáticas: autoridade tradicional, cultura, economia informal, educação, estudos de género, etnicidade e identidade cultural, desenvolvimento, desigualdades sociais, direitos humanos, família, meios de comunicação, migrações, modernidade, mudança social, nacionalismo, política, religião, saberes endógenos, saúde, urbanização etc.

No entender de Elísio Macamo, "todas as áreas pelas quais a sociologia se interessa são de potencial interesse para uma sociologia africana" (MACAMO, 2002, p. 17-18). Porém, acrescenta que as condições de possibilidade desta sociologia se destacam em quatro áreas: (i) a transformação social; (ii) a sociologia do conhecimento; (iii) a sociologia rural; e (iv) a sociologia do quotidiano (MACAMO, 2002).

Quanto aos usos da sociologia africana, as opiniões variam de autor para autor. Uns defendem uma sociologia interventiva e outros, não. Por exemplo, Macamo defende que "a concepção duma sociologia das sociedades africanas não devia ter como 
base o princípio de resolução de problemas" (MACAMO, 2002, p. 18). Por sua vez, em Matumona e em Nga Ndongo, encontram-se a apologias a uma sociologia africana interventiva. Ei-las: a sociologia africana "é promovida pelos africanos e é dirigida para eles, concentrando-se no seu mundo - a África que, actualmente, vive momentos conturbados, precisando de apoio das ciências sociais para a sua reabilitação" (MATUMONA, 2008, p. 30); e a sociologia africana é "uma apropriação por africanos, de um conhecimento que, tendo servido por muito tempo à sua opressão, deve, a partir de então, constituir o instrumento por excelência da sua libertação" (NGA NDONGO, 2017).

Os meandros da investigação africana em ciências sociais revelam que hoje, para o bem e para o mal, "a sociologia, e as ciências sociais em geral, são domínios científicos consolidados em muitos países africanos" e, quanto à sociologia africana, "enquanto ordenamento do conhecimento sociológico protagonizado pelos próprios africanos, é já uma realidade" (VENÂNCIO, 2000: 28). Uma realidade que sai do genitivo do objecto ao genitivo do sujeito e vice-versa.

\section{CONSIDERAÇÕES FINAIS}

Este texto objectivou reflectir sobre a sociologia africana, enquanto área de investigação e de ensino, tendo em atenção o processo de formação, desenvolvimento, profissionalização e afirmação desta ciência social em África e enfatizando dois casos genitivos (genitivo do objecto e genitivo do sujeito) norteadores dos debates em torno do problema do status epistemológico da sociologia africana.

Demarcando-se das discussões a respeito da essência africana, propõe-se a prática de uma sociologia africana que constrói pontes e não a de uma sociologia que derruba pontes e ergue muros entre o africano e o não-africano. São os problemas sociais e as realidades sociais africanas que fornecem elementos para uma reflexão sociológica afrocentrada. Porém, isto não descarta a necessidade de dialogar criticamente com a sociologia do norte epistemológico.

As múltiplas faces das sociedades africanas impõem sobre a sociologia africana toda uma necessidade de dialogar com as diversas disciplinas que têm o continente 
africano como objecto de estudo, por intermédio de uma atitude inter-, trans- e multidisciplinar.

Actualmente, a sociologia em África está institucionalizada e profissionalizada. Tem os seus actores, instituições, revistas e redes de investigação. Embora não os tenha com a quantidade e a qualidade desejadas, tem registado avanços consideráveis.

A sociologia africana, enquanto campo de estudo, consta no currículo dos cursos de sociologia de várias instituições de ensino superior em África. E isto é susceptível de contribuir para a conscientização a respeito do papel da prática de uma sociologia africana por parte dos sociólogos africanos, bem como dos profissionais envolvidos no processo de ensino e aprendizagem da sociologia em África, para mitigar os efeitos da dependência académica e para resistir ao eurocentrismo e ao imperialismo académico da actual geopolítica da produção do conhecimento.

\section{REFERÊNCIAS BIBLIOGRÁFICAS}

ADESINA, Jimi O. Práticas da Sociologia Africana: Lições de endogeneidade e género na academia. In: CRUZ E SILVA, Teresa; COELHO, João Paulo Borges; SOUTO, Amélia Neves de (Orgs.). Como fazer ciências sociais e humanas em África: Questões epistemológicas, metodológicas, teóricas e políticas. Dakar: CODESRIA, 2012, pp. 195-209.

ADESINA, Jimi O. Archie Mafeje and the pursuit of endogeneity: Against alterity and extroversion. Africa Development, vol. XXXIII, n. ${ }^{\circ} 4$, 2008, pp. 133-152.

ADESINA, Jimi O. Sociology and Yorùbá Studies: Epistemic intervention or doing sociology in the 'vernacular'?. African Sociological Review, vol. 1, n. ${ }^{\circ}$ 2, 2002, pp. 91-114.

AKIWOWO, Akinsola. Universalism and indigenization in Sociological Theory. International Sociology, vol. 3, n. ${ }^{\circ}$, 1998, pp. 155-160.

AKIWOWO, Akinsola. Contribution to the sociology of knowledge from an African oral poetry. In: ALBROW, Martin; KING, Elizabeth (Eds.). Globalization, knowledge and society. London: SAGE publications, 1990, pp. 103-117.

AKIWOWO, Akinsola. Building national sociological tradition in an African subregion. In: GENOV, Nikolai (Ed.). National tradition in sociology. London: SAGE publications, 1989, pp. 151-166.

AKIWOWO, Akinsola. Trend Report: Sociology in Africa Today. Current Sociology, vol. 28, n. ${ }^{\circ} 2,1980$, pp. 2-73.

ALATAS, Syed Farid. Ibn Khaldun (1332-1406). In: ALATAS, Syed Farid; SINHA, Vineeta. Sociological Theory Beyond The Canon. London: Palgrave Macmillan, 2017, pp. 17-45. 
ALATAS, Syed Farid. Academic dependency and the global division of labour in the Social Sciences. Current Sociology, 51 (6), 2003, pp. 599-613.

ALATAS, Syed Hussein. Intellectual imperialism: Definition, traits and problems. Southeast Asian Journal of Social Science, 28(1), 2000, pp. 23-45.

ALATAS, Syed Hussein. The captive mind in development studies: Some neglected problems and the need for an autonomous social science tradition in Asia. International Social Science Journal, vol. XXIV, n. ${ }^{\circ}$ 1, 1972, pp. 9-25.

BALANDIER, Georges. Sociologia da África Negra. Dinâmica das mudanças sociais na África Central, Luanda: Edições Mulemba; Ramada: Edições Pedago, 2014.

CARDOSO, Carlos. Desenclavar as Ciências Sociais na África lusófona: a iniciativa especial do CODESRIA. Revista de Antropologia da Universidade de São Paulo, vol. 60, n. ${ }^{\circ} 3,2017$, pp. $89-111$.

CARDOSO, Carlos. Da possibilidade das ciências sociais em África. In: CRUZ E SILVA, Teresa; COELHO, João Paulo Borges; SOUTO, Amélia Neves de (Orgs.). Como fazer ciências sociais e humanas em África: Questões epistemológicas, metodológicas, teóricas e políticas. Dakar: CODESRIA, 2012, pp. 125-144.

CHENNTOUF, Tayeb. La sociologie au Maghreb: Cinquante ans après. Revue Africaine de Sociologie, vol. 10, n. ${ }^{\circ} 1,2006$, pp. 1-30.

CONNELL, Raewyn. O império e a criação de uma ciência social. Contemporânea, vol. 2 , n. ${ }^{\circ}$ 2, 2012, pp. 309-336.

DEVÉS-VALDÉS, Eduardo. O pensamento africano subsaariano: Conexões e paralelos com o pensamento latino-americano e asiático (um esquema). Rio de Janeiro: EDUCAM e CLACSO, 2008.

DIOP, Babacar Mbaye; DIENG, Doudou (Org.). A consciência histórica africana. Luanda: Edições Mulemba; Ramada: Edições Pedago, 2014.

DORTIER, Jean-François (Dir.). Uma história das ciências humanas. Lisboa: Edições Texto \& Grafia, 2009.

ELA, Jean-Marc. Investigação científica e crise da racionalidade (livro I). Luanda: Edições Mulemba; Ramada: Edições Pedago, 2015a.

ELA, Jean-Marc. As culturas africanas no âmbito da racionalidade científica (livro II). Luanda: Edições Mulemba; Ramada: Edições Pedago, 2015b.

ELA, Jean-Marc. A investigação africana face ao desafio da excelência científica (livro III). Luanda: Edições Mulemba; Ramada: Edições Pedago, 2015c.

ELA, Jean-Marc. Restituir a história às sociedades africanas. Promover as ciências sociais na África Negra, Luanda: Edições Mulemba; Ramada: Edições Pedago, 2013.

GONÇALVES, Jonuel. Manual de estudo sobre África, Luanda: Mayamba Editora, 2016. 
GONÇALVES, José. As ciências sociais em Angola, Cabo Verde, Guiné-Bissau, Moçambique e São Tomé e Príncipe. In: CODESRIA, Ciências sociais em África. Alguns projectos de investigação, Dakar: CODESRIA, 1992, pp. 13-61.

HEIMER, Franz-Wilhelm. Reflexões acerca de uma abordagem interdisciplinar das sociedades africanas. Cadernos de Estudos Africanos, n. ${ }^{\circ}$ 3, 2002, pp. 153-159.

HOUNTONDJI, Paulin J. Conhecimento de África, conhecimentos de africanos: Duas perspectivas sobre os Estudos Africanos. In: SANTOS, Boaventura de Sousa; MENESES, Maria Paula (Orgs.). Epistemologias do sul. Coimbra: Edições Almedina, 2009, pp. 119-129.

KAJIBANGA, Víctor. Notas sobre a "problemática" da filosofia africana. In: SERRA, Carlos (Coord.). O que é filosofia africana?. Lisboa: Escolar Editora, 2015, pp. 11-38.

KAJIBANGA, Víctor. Liberdades académicas e responsabilidade social dos universitários africanos. Revista Angolana de Sociologia, n 1, Jun., 2008a, pp. 73-83.

KAJIBANGA, Víctor. Saberes endógenos, ciências sociais e desafios dos países africanos. Revista Angolana de Sociologia, nº 2, Dez., 2008b, pp. 7-14.

LAWUYI, O. B.; TAIWO, Olufemi. Toward an African sociological tradition: A rejoinder to Akinsolo and Makinde. In: ALBROW, Martin; KING, Elizabeth (Eds.). Globalization, knowledge and society. London: SAGE publications, 1990, pp. 135-151.

MACAMO, Elísio. A constituição duma sociologia das sociedades africanas. Estudos Moçambicanos, n. ${ }^{\circ}$ 19, 2002, pp. 5-26.

MAKGOBA, Malegapuru William (Org.) Renascença africana. A nova luta, Luanda: Edições Mulemba; Ramada: Edições Pedago, 2016.

MAKINDE, M. Akin. Asuwada principle: An analysis of Akiwowo's contributions to the sociology of knowledge from an African perspective. In: ALBROW, Martin; KING, Elizabeth (Eds.). Globalization, knowledge and society. London: SAGE publications, 1990, pp. 119-134.

MARTINS, Elcimar Simão et al. (Etno)ciência africana: uma epistemologia a partir do pensamento dos dogons. Revista da ABPN, v. 11, Ed. Especial - Caderno Temático: "Saberfazer em Ciências \& Tecnologias - Trajetórias Afrodiaspóricas”, Dezembro, 2019, p. 71-89.

MATUMONA, Muanamosi. A sociologia africana no mundo lusófono. Fundamentos para um novo paradigma epistemológico. Revista Angolana de Sociologia, n. ${ }^{\circ}$ 2, 2008, pp. 15-33.

MBEMBE, Achille. As formas africanas de auto-inscrição. Estudos Afro-Asiáticos, ano 23, no 1, 2001, pp. 171-209.

MERLEN, Sebastião. Epistemologias contra-hegemônicas e pedagogias descolonizadoras: elementos para uma descolonização do ensino da sociologia em Angola. In: JESUS, Leandro Santos Bulhões de Jesus; BARROS, Miguel de; FILICE, Renísia Cristina Garcia (Orgs.). Tecendo redes antirracistas II: contracolonização e soberania intelectual. Fortaleza: Imprensa Universitária da Universidade Federal do Ceará (UFC), 2020, pp. 161-186.

MLAMBO, Alois S. Western social sciences and Africa: The domination and marginalization of a continent. African Sociological Review, vol. 10, n. ${ }^{\circ}$ 1, 2006, pp. 161-179. 
MOURÃO, Fernando. Múltiplas faces da identidade africana. África - Revista do Centro de Estudos Africanos da Universidade de São Paulo, vol. 18-19, n. ${ }^{\circ}$ 1, 1995/1996, pp. 5-21.

MUNANGA, Kabengele. Antropologia africana: Mito ou realidade?. Revista de Antropologia, n. ${ }^{\circ} 26,1983$, pp. 151-160.

NGA NDONGO, Valentin. La sociologie camerounaise. Un demi-siècle de lente mais dynamique construction, Paris: L'Harmattan, 2017.

NGA NDONGO, Valentin. La Sociologie en Afrique Centrale: Etats des lieux, problèmes et perspectives. Revue Africaine de Sociologie, vol. 10, n. ${ }^{\circ}$ 1, 2006, pp. 31-58.

PIMENTA, Carlos \& KAJIBANGA, Víctor. Epistemologia dos Estudos Africanos. Comunicação apresentada na Conferência Internacional "Conhecimentos endógenos e a construção do futuro em África», no Porto, 15 e 16 de Abril de 2011, pp 1-20.

SANDA, A. Muyiwa. In defence of indigenisation in sociological theories. International Sociology, vol. 3, n. ${ }^{\circ}$, 1988, pp. 189-199.

TAMBA, Moustapha. Sociologie au Sénégal, Paris: L’Harmattan, 2014.

VENÂNCIO, José Carlos. O facto africano. Elementos para uma Sociologia de África. Lisboa: Veja, 2000.

WAAST, Roland; RICHARD-WAAST, Claire; ROSSI, Pier L. What do social sciences in North African countries focus on?. In: International Social Science Council. World Social Science Report: Knowledge Divides, Paris: UNESCO Publishing, 2010, pp. 176-179.

Recebido em: 02/12/2020

Aprovado em: 01/10/2021 